\title{
The growth of sublimation crystals and surface hoar on the Antarctic plateau
}

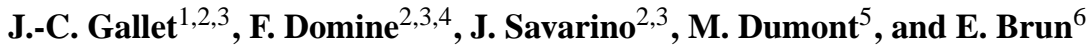 \\ ${ }^{1}$ Norwegian Polar Institute, Troms $\varnothing$, Norway \\ ${ }^{2}$ CNRS, LGGE, 38041 Grenoble, France \\ ${ }^{3}$ Université Grenoble Alpes, LGGE, 38041 Grenoble, France \\ ${ }^{4}$ Takuvik Joint International Laboratory and Department of Chemistry, Université Laval and CNRS, Quebec, Canada \\ ${ }^{5}$ Météo-France-CNRS, CNRM-GAME UMR 3589, CEN, Saint-Martin d'Hères, France \\ ${ }^{6}$ Météo-France-CNRS, CNRM-GAME UMR 3589, Toulouse, France \\ Correspondence to: F. Domine (florent.domine@gmail.com)
}

Received: 26 November 2013 - Published in The Cryosphere Discuss.: 13 December 2013

Revised: 2 May 2014 - Accepted: 30 May 2014 - Published: 14 July 2014

\begin{abstract}
On the Antarctic plateau, precipitation quantities are so low that the surface mass budget is for an important part determined by exchanges of water vapor between the snow surface and the atmosphere surface. At Dome C $\left(75^{\circ} \mathrm{S}, 123^{\circ} \mathrm{E}\right)$, we have frequently observed the growth of crystals on the snow surface under calm sunny weather. Here we present the time variations of specific surface area (SSA) and density of these crystals. Using the detailed snow model Crocus, we conclude that the formation of these crystals was very likely due to the nighttime formation of surface hoar crystals and to the daytime formation of sublimation crystals. These latter crystals form by processes similar to those involved in the formation of frost flowers on young sea ice. The formation of these crystals impacts the albedo, mass and energy budget of the Antarctic plateau. In particular, the SSA variations of the surface layer can induce an instantaneous forcing at the snow surface up to $-10 \mathrm{~W} \mathrm{~m}^{-2}$ at noon, resulting in a surface temperature drop of $0.45 \mathrm{~K}$. This result confirms that snow SSA is a crucial variable to consider in the energy budget and climate of snow-covered surfaces.
\end{abstract}

\section{Introduction}

Snow is one of the most, or perhaps even the most reflective surface on earth. It can cover up to $50 \%$ of land masses in the Northern Hemisphere in winter (Robinson et al., 1993), and nearly all of Greenland and Antarctica year-round. Snow, therefore, considerably affects the energy budget of the earth.

At temperatures below $0{ }^{\circ} \mathrm{C}$, snow is a porous medium made of air, ice and small amounts of impurities. Because of the large surface area of the ice-air interface, snow is thermodynamically unstable and is therefore in constant evolution, the most visible modifications being changes in the shapes and sizes of snow grains. The set of physical processes responsible for these modifications is called metamorphism (Colbeck, 1982). Metamorphism also affects macroscopic physical properties such as density, thermal conductivity, and albedo.

In the visible part of the electromagnetic radiation spectrum $(400-700 \mathrm{~nm})$, snow albedo is mostly dependant on its impurity content while it depends on the size of the snow grains in the infrared part of the solar spectrum (Warren, 1982). The size of the snow grains usually increases during metamorphism (Taillandier et al., 2007; Flanner and Zender, 2006) so that, in general, snow albedo decreases over time. Understanding snow grain size variations is therefore crucial for an accurate calculation of the earth's energy budget.

Given the complex shapes of snow particles, defining grain size unambiguously has been difficult (Aoki et al., 2000). However, it has been shown that the albedo of non-spherical particles was adequately represented by a collection of spherical particles having the same surface to volume $(S / V)$ ratio as the non-spherical particles, and the size of those spheres define the optical radius $r_{\text {opt }}$ unambiguously (Grenfell and 
Warren, 1999). For optical calculations, $r_{\mathrm{opt}}$ of snow crystals has been used successfully. In practice, $r_{\text {opt }}$ can be obtained by measuring the specific surface area (SSA) of the snow, defined as the surface area of the air-ice interface per unit mass: $\mathrm{SSA}=S / M=S /\left(\rho_{\text {ice }} V\right)$, where $S$ is the interface surface area, $M$ the mass and $\rho_{\text {ice }}$ is the ice density, $917 \mathrm{~kg} \mathrm{~m}^{-3}$ at $0^{\circ} \mathrm{C}$. Treating snow crystals as spheres, we then have $\mathrm{SSA}=3 /\left(\rho_{\text {ice }} r_{\mathrm{opt}}\right)$, and SSA measurements have been used successfully for albedo calculations (Gallet et al., 2011). Snow SSA is expressed in units of $\mathrm{m}^{2} \mathrm{~kg}^{-1}$. A compilation of measured values ranges from $2 \mathrm{~m}^{2} \mathrm{~kg}^{-1}\left(r_{\mathrm{opt}}=1.64 \mathrm{~mm}\right)$ for melt-freeze crusts to $156 \mathrm{~m}^{2} \mathrm{~kg}^{-1}\left(r_{\mathrm{opt}}=21.0 \mu \mathrm{m}\right)$ for fresh dendritic crystals (Domine et al., 2007b). Recently, a value of $223 \mathrm{~m}^{2} \mathrm{~kg}^{-1}\left(r_{\mathrm{opt}}=14.7 \mu \mathrm{m}\right)$ has been measured for diamond dust crystals (i.e., clear sky precipitation) in the Arctic (Domine et al., 2011b).

On a daily time scale, variations of the factors affecting the energy budget of the Antarctic ice cap (Van As et al., 2005; Van den Broeke et al., 2006) can result in sublimation and condensation of water vapor at the surface. These physical processes result in modifications of the size and shape of snow crystals, and therefore of their SSA. Since SSA determines albedo, this variable contributes to daily albedo variations. Other crucial variables that cause daily albedo variations include the solar zenith angle (Warren, 1982). Previous field studies have indeed observed daily variations in snow albedo in Antarctica, (McGuffie and HendersonSellers, 1985; Pirazzini, 2004) but detailed interpretations in terms of quantitative snow surface properties could not be made because among other factors, snow SSA was not measured. On the Antarctic plateau, far from any source of impurities (Warren and Clarke, 1990), snow albedo can in theory be calculated using snow SSA only in the case of a semiinfinite homogeneous layer. In the case of a complex stratified snowpack, the SSA, thickness and density of each layer must be known (Zhou et al., 2003).

During summer campaigns at Dome Concordia (Dome C, $75^{\circ} 06^{\prime} \mathrm{S}, 123^{\circ} 20^{\prime} \mathrm{E}, 3233 \mathrm{~m}$ a.s.l.) on the East Antarctic plateau, under calm and sunny weather, we frequently observed the rapid growth of spike-like crystals that are clustered with other structures of different shape, in the absence of detectable precipitation. The size of the clusters appeared stable and they can persist for several weeks at a time. They usually disappear when they are blown off by strong winds. We initially thought that they were surface hoar crystals, which very commonly grow on any snow surface that cools radiatively in the absence of strong winds (Cabanes et al., 2002). Surface hoar crystals are formed by the deposition of atmospheric vapor water over the surface of the snowpack and often results in small striated and hollow crystals. To study the impact of these crystals on the radiative budget of the surface, we undertook measurement of their SSA and density. From our initial results, we inferred that these clusters probably did not result only from surface hoar formation, and that sublimation crystals, as observed by Gow (1965),
Orheim (1968) and Weller (1969), were probably forming. Sublimation crystals are formed by an upward flux of water vapor coming from the warmer snowpack into the cooler air that condenses at the surface of the snowpack. To avoid confusion between surface hoar and sublimation crystals, we will avoid the term of "frost" in this paper. To better characterize the possibility of forming sublimation crystals on the Antarctic plateau, we used the Crocus snow model (Vionnet et al., 2012) and the formalism of Style and Worster (2009). We report here these field and modeling studies and attempt to derive implications for the energy and mass balance of the Antarctic plateau.

\section{Experimental and modeling methods}

\subsection{Experimental}

The study took place at the French-Italian base of Dome C, on 18-19 January 2009. An area of about $16 \mathrm{~m}^{2}$ was used for this study. A fairly flat and planar area was chosen to reduce the effects of surface roughness (i.e., sastrugi). Specific surface area measurements were done using the DUFISSS instrument (DUal Frequency Integrating Sphere for Snow SSA measurements) described in Gallet et al. (2009). Briefly, the principle of the method is to measure snow hemispherical reflectance at 1310 or $1550 \mathrm{~nm}$ with an integrating sphere. The SSA-reflectance relationship was determined from simultaneous SSA measurements using $\mathrm{CH}_{4}$ adsorption (Legagneux et al., 2002). The method can be used on all snow types and its accuracy is $10 \%$ at the $95 \%$ confidence level. In all cases, triplicate samples were measured to minimize errors and the effects of spatial variability. To measure the SSA of surface snow with a $1 \mathrm{~cm}$ resolution, the sampling protocol of Gallet et al. (2009) was modified. Briefly, snow was delicately sampled with a spatula and placed into the sample holder, a cylindrical cup $63 \mathrm{~mm}$ in diameter and $25 \mathrm{~mm}$ deep. Since in all cases the snow was soft and non-cohesive, this sampling did not result in structural modifications. The excess snow was shaved off with a spatula, so that the sample presented a perfectly flat surface. Other aspects of the protocol are as described in Gallet et al. (2009). The sample holder was placed against the nadir port of the sphere, where it was illuminated with a $1310 \mathrm{~nm}$ laser diode. The reflected light was measured with an InGaAs photodiode. The signal was calibrated with six reflectance standards.

Measuring the density of $1 \mathrm{~cm}$-thick snow layers is an extremely delicate process. Here we weighed the sample holder used for SSA measurements. Great care was taken not to compact or otherwise perturb snow structure, which was possible because snow grains were only very loosely bonded. Evaluating a measurement error using this method is a delicate task because we certainly introduce systematic errors. Typical uncertainty in snow density measurements made by weighing a known volume are about $10 \%$ (Conger 
and McClung, 2009). Given the extra process of transferring snow into a container with a spatula, we estimate that the overall uncertainty in our density measurements was $20 \%$. Visual snow observations were performed using an $8 \mathrm{X}$ magnifying glass. Efforts were done to carefully identify the various crystal types found and their proportions.

Data for meteorological variables are available at Dome C. An infrared sensor yielded snow surface temperature. Air temperature at $2 \mathrm{~m}$ and wind speed are also observed with an automatic weather station (AWS). Errors of these measurements are caused, among other things, by radiative heating of the shelter housing the thermometer (Genthon et al., 2010) and inaccuracy in the reference black body of the IR sensor. Overall, we estimate that the accuracy is $1.5^{\circ} \mathrm{C}$ for the air and snow skin temperatures. We also used temperature, humidity and wind speed data at $4 \mathrm{~m}$ height from the $45 \mathrm{~m}$ height tower where sensors are ventilated as detailed by Genthon et al. (2010).

\subsection{Modeling}

In order to investigate the relative impact of various surface processes leading to condensation or sublimation of vapor water at the snow-air interface, we used the detailed snowpack model Crocus (Vionnet et al., 2012). Crocus is a multilayered one-dimensional snowpack model with an elaborate description of the energy budget of the snowpack, including surface energy and mass balance. Each layer is characterized by its density, thickness, size and shape of grains, temperature and liquid water content. Snow metamorphism in Crocus is represented by semi-empirical variables and is simulated for each layer using the temperature, the temperature gradient and the liquid water content. The water vapor exchanges inside the snowpack, i.e., from one layer to the next, are not explicitly accounted for in this model. However, water vapor exchanges between the snow surface and the atmosphere are taken into account. Solar radiation penetration is computed as a function of snow optical radius and age, i.e., number of days since snowfall. Age is in fact used as a surrogate for aerosol deposition. Due to the very low level of impurities on the high Antarctic plateau, Crocus simulations in this study were done without accounting for the effect of age on the solar penetration and albedo. Solar radiation is modeled over three spectral bands: $0.3-0.8,0.8-1.5$ and $1.5-2.8 \mu \mathrm{m}$. The incoming broadband solar irradiance is provided by ERAInterim (Dee et al., 2011). It is separated across the three bands using fixed coefficients and radiation is entirely diffuse. The vertical resolution in the snow is not fixed since it corresponds to the layering of the snowpack controlled by the model (Vionnet et al., 2012). Despite these rather simplistic assumptions, as demonstrated in Brun et al. (2011), Crocus allows a good simulation of the vertical sub-surface temperature profile at Dome $\mathrm{C}$ and surface temperature in Antarctica (Freville et al., 2014). Finally, Crocus takes as input the meteorological variables that constrain the surface mass and energy balance of the snowpack: air temperature, specific humidity, wind speed, shortwave and long-wave incoming radiation and precipitation amount and phase.

Brun et al. (2011) have carried out Crocus simulations at Dome C. In their study two types of simulations were done, i.e., stand alone simulations forced by local meteorological variables over a period of ten days and coupled simulations with the atmospheric model AROME. They showed that the model reproduces the observed downward propagation of the diurnal heat wave into the upper $50 \mathrm{~cm}$ of the snowpack and the snow surface temperature reasonably well.

In this study, we used the meteorological variables provided by ERA-Interim reanalysis (Dee et al., 2011). These data are provided on a $3 \mathrm{~h}$ time step and have been processed as in Brun et al. (2013). Operational analyses from the European Centre for Medium-Range Weather Forecasts (ECMWF) similar to ERA-Interim have been evaluated at Dome $\mathrm{C}$ with respect to field measurements of temperature, humidity and wind speed at different levels on a $45 \mathrm{~m}$ tower by Genthon et al. (2010). They determined a small warm bias of temperature relative to observations for all height. The amplitude of the diurnal cycle of relative humidity was also overestimated.

A first Crocus simulation was initialized with a $30 \mathrm{~m}$ thick snowpack with similar snow physical properties as in Brun et al. (2011). This simulation was performed over two years (1 January 2007 to 1 January 2009) to initialize properly the deep snowpack temperature profile. As field data are not available for the whole two year period, we used ERAInterim forcing data to initialize the snowpack. Thereafter, from 1 to 20 January 2009, we used wind speed, humidity and temperature (ventilated sensors), measured $4 \mathrm{~m}$ above ground at the tower instead of ERA-Interim as input for Crocus. A small difference in the forcing was indeed observed on 1 January 2009, but its effect on the snowpack variable vanishes within a few days, and our experiment starts on 18 January. In addition, the density of the upper $2 \mathrm{~cm}$ of the simulated snowpack was changed to the mean density values measured during the period, i.e., $141 \mathrm{~kg} \mathrm{~m}^{-3}$ measured for the first centimeter instead of $98 \mathrm{~kg} \mathrm{~m}^{-3}$ modeled and $236 \mathrm{~kg} \mathrm{~m}^{-3}$ for the second centimeter instead of $210 \mathrm{~kg} \mathrm{~m}^{-3}$.

Crocus features neither a detailed treatment of condensation or sublimation of water vapor in terms of snow microstructural properties, nor a representation of water vapor exchange between layers. Thus the purpose of the model run presented here is not an attempt to reproduce the daily variations in surface SSA but rather an exploration of the physical conditions leading to such variations. 

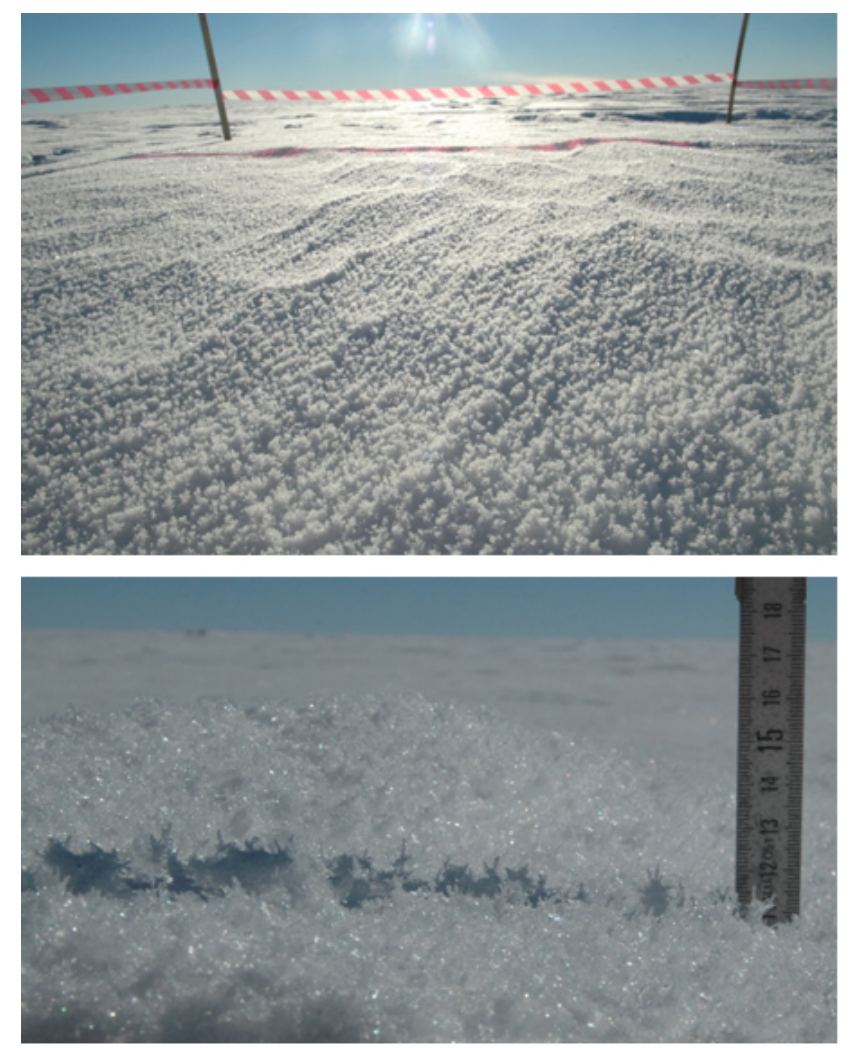

Figure 1. Sublimation crystals and surface hoar crystals on the surface of the snowpack at Dome C on 18 January 2009.

\section{Results}

\subsection{Experimental}

Our January 2009 study took place under clear sky conditions. The surface was covered with crystals that closely resembled sublimation and surface hoar crystals as described in Gow (1965), Orheim (1968) and Weller (1969). Observations (Fig. 1) revealed clusters of crystals presenting both faceted and rounded parts. Sharp points, sometimes with dendritelike outgrowths, were often sticking out of those clusters. Faceted crystals, which resembled typical surface hoar crystals, were often observed between and on those clusters. Faceted rounded crystals, following the terminology of Fierz et al. (2009), were also observed. A quantitative estimation of the proportion of such mixture is not very realistic, and we will explain the reasons in this work. During this study, the clusters covered the whole surface as far as the eye could see, and definitely were not limited to the area around the base.

SSA and density data are shown in Fig. 2a, and the numerical values are detailed in Table 1 . The SSA of the first $\mathrm{cm}$ increases in the evening of 18 January (event I.1) and also at noon on 19 January (event I.2), respectively by 23 and $13 \%$ relative to the previous measurement. Specific surface area decreases at midday on both days (events D.1 and D.2), respectively by 17 and $20 \%$. For the second cm, SSA remains almost constant on 18 January. On 19 January, a $30 \%$ increase is first observed, followed by a $30 \%$ decrease, and finally an increase in the very last part of the study. The observed variations are greater than the measurement uncertainty of $10 \%$.

The density of the first $\mathrm{cm}$ varies around $140 \mathrm{~kg} \mathrm{~m}^{-3}$, while that of the second $\mathrm{cm}$ is around $240 \mathrm{~kg} \mathrm{~m}^{-3}$. In general, density and SSA appear anti-correlated. If we look in more detail at the density measurements between 18 and 19 January, we observe a decrease of 20 and $30 \%$, respectively for the first and the second $\mathrm{cm}$ over the first $24 \mathrm{~h}$ of the study. This is greater or equal than our estimated accuracy of $20 \%$.

Figure $2 \mathrm{~b}$ shows that the air temperature peaked around 16:00 and was minimal around 04:00 (dashed curve). In the following, all data and figures refer to Dome $\mathrm{C}$ local time (LT) that is GMT +8:00. During this study, the wind speed was low (green curve) and the sky remained clear, except for occasional thin cirrus covering less than $10 \%$ of the sky. Snow skin temperature (black curve) varied between $-31^{\circ} \mathrm{C}$ at noon and $-47^{\circ} \mathrm{C}$ between 02:00 and 03:00.

\subsection{Simulated surface mass and energy balance}

The snow surface temperature simulated by Crocus was evaluated with respect to the measurements of the IR sensor (Fig. 2b). The mean bias over the three days of simulation is $0.3 \mathrm{~K}$, the root mean square deviation is $1.49 \mathrm{~K}$. Given the potential errors of measuring temperature from IR emission, in part due to errors of snow emissivity (Bintanja and Vandenbroeke, 1995), this shows that Crocus provides a reasonable estimate of the snow surface temperature. A similar conclusion was reached by Brun et al. (2011) and Freville et al. (2014)

Figure 3 presents the modeled vertical profiles of temperature for the upper layers of the snowpack for different times of the day for 18 and 19 January 2009. The evolution of the vertical profile is similar for both days with maximum surface temperature around noon. During the day, the warmest point of the profile is located about $1 \mathrm{~cm}$ below the snow surface. This is a direct consequence of the coupled effect of solar radiation which penetrates inside the snowpack and radiative cooling under clear sky conditions that occurs at the surface (Colbeck, 1989). This induces a strong temperature gradient around noon in the uppermost part of the snowpack.

Atmospheric latent and sensible heat fluxes together with the net radiation budget at the snow surface and the subsurface heat flux are reported in Fig. 4 for the three days of simulations. Sensible and radiative fluxes are positive in the daytime so that the atmosphere expectedly heats up during the day, as well as the snow surface due to a positive radiation budget. The latent heat flux also shows a diurnal cycle, with night time condensation alternating with daytime sublimation. Although sublimation leads to mass loss, it can under 
Table 1. SSA and density values used in DISORT for albedo calculations for 18-19 January. Standard deviations are calculated from triplicates measurements, for density and SSA.

\begin{tabular}{|c|c|c|c|c|}
\hline \multicolumn{5}{|c|}{ First centimeter } \\
\hline $\begin{array}{l}\text { Date and Time } \\
(\mathrm{GMT}+08: 00)\end{array}$ & $\begin{array}{l}\text { Mean SSA } \\
\mathrm{m}^{2} \mathrm{~kg}^{-1}\end{array}$ & $\begin{array}{l}\text { SSA standard } \\
\text { deviation }\end{array}$ & $\begin{array}{l}\text { Mean density } \\
\mathrm{kg} \mathrm{m}^{-3}\end{array}$ & $\begin{array}{c}\text { Density standard } \\
\text { deviation }\end{array}$ \\
\hline 18 Jan $2009,11: 00$ & 40.0 & 1.2 & 156 & 8 \\
\hline 18 Jan $2009,14: 30$ & 33.3 & 0.5 & 165 & 4 \\
\hline 19 Jan 2009, 00:00 & 40.9 & 1.8 & 147 & 8 \\
\hline 19 Jan $2009,04: 30$ & 39.7 & 2.3 & 145 & 10 \\
\hline 19 Jan $2009,11: 30$ & 46.3 & 1.0 & 125 & 5 \\
\hline 19 Jan $2009,17: 10$ & 36.8 & 0.7 & 130 & 6 \\
\hline 19 Jan $2009,21: 00$ & 37.0 & 1.1 & 133 & 4 \\
\hline 20 Jan $2009,01: 20$ & 37.8 & 0.9 & 133 & 4 \\
\hline \multicolumn{5}{|c|}{ Second centimeter } \\
\hline $\begin{array}{l}\text { Date and Time } \\
(\mathrm{GMT}+08: 00)\end{array}$ & $\begin{array}{l}\text { Mean SSA } \\
\mathrm{m}^{2} \mathrm{~kg}^{-1}\end{array}$ & $\begin{array}{l}\text { SSA standard } \\
\text { deviation }\end{array}$ & $\begin{array}{l}\text { Mean density } \\
\mathrm{kg} \mathrm{m}^{-3}\end{array}$ & $\begin{array}{c}\text { Density standard } \\
\text { deviation }\end{array}$ \\
\hline 18 Jan $2009,11: 00$ & 25.6 & 1.2 & 290 & 6 \\
\hline 18 Jan $2009,14: 30$ & 25.4 & 0.7 & 258 & 3 \\
\hline 19 Jan 2009, 00:00 & 24.7 & 0.6 & 235 & 16 \\
\hline 19 Jan $2009,04: 30$ & 26.5 & 0.9 & 236 & 13 \\
\hline 19 Jan $2009,11: 30$ & 32.1 & 1.1 & 202 & 13 \\
\hline 19 Jan $2009,17: 10$ & 23.2 & 0.7 & 215 & 7 \\
\hline 19 Jan 2009, 21:00 & 25.1 & 0.3 & 227 & 10 \\
\hline 20 Jan $2009,01: 20$ & 28.3 & 0.6 & 231 & 11 \\
\hline
\end{tabular}

certain conditions also lead to the formation of frost flowers over young sea ice (Style and Worster, 2009; Domine et al., 2005; Perovich and Richter-Menge, 1994) or sublimation crystals over the snow surface (Gow, 1965; Weller, 1969), as observed here.

To investigate the environmental conditions favorable for various types of ice crystals' formation, we used the classification described by Style and Worster (2009) which includes six regimes of possible behavior of an air-ice system in terms of water vapor exchange (Fig. 3 of Style and Worster, 2009). These regimes depend on the saturation ratio of the atmosphere a few meters above the surface (a region called far field by Style and Worster, 2009), $\pi=p_{\infty} / p_{\text {sat }}\left(T_{\infty}\right)$, where $p_{\infty}$ is the water vapor pressure of the far field and $p_{\text {sat }}\left(T_{\infty}\right)$ is the saturation pressure at the far-field temperature, and of the difference between the far field air temperature, $T_{\infty}$ and the temperature of the surface, $T_{i}$. Note that at Dome $\mathrm{C}$, the air temperature is always below freezing so that the saturation ratio is calculated with respect to solid ice. In our case, the atmosphere is always undersaturated $\left(p_{\infty} / p_{\text {sat }}\left(T_{\infty}<1\right)\right.$ at $4 \mathrm{~m}$ above the surface. Therefore, only four of the six regimes described by Style and Worster (2009) in their Table 1 need to be considered. The environmental conditions needed for each of these regimes can be described as a function of the value of $\mu=\left(T_{\infty}-T_{i}\right) / T_{\infty}$ and $m=\mathrm{ML} /\left(\mathrm{RT}_{\infty}\right)$, where $\mathrm{ML}=50.9 \mathrm{~kJ} \mathrm{~mol}^{-1}$ is the molar heat of sublimation of ice and $R=8.31 \mathrm{~J} \mathrm{~K}^{-1} \mathrm{~mol}^{-1}$ is the gas constant. These conditions are reported in Table 2 .

Figure 5 depicts the typical snow and air temperature profiles during daytime for a clear sky day together with profiles of vapor pressure and saturation vapor pressure. As shown in this schematic diagram, a supersaturation region can exist just above the surface where the vapor pressure is greater than the saturation vapor pressure (Style and Worster, 2009). The local supersaturation in the air just above the ice happens because of the strong non-linear relationship between temperature and saturation vapor pressure. This local supersaturation can induce water vapor fluxes responsible for the formation of sublimation crystals. This process has been frequently reported on sea ice, with the formation of large crystals called frost flowers (Perovich and Richter-Menge, 1994; Domine et al., 2005). Over sea ice, the growth of frost flowers occurs over brine-covered surfaces so that a nucleation problem arises, resulting in a partial coverage of frost flowers over the ice, as observed by Perovich and Richtermenge (1994). In our case, the growth of sublimation crystals occurs over the snow surface so that the number of possible nucleation sites is unlimited once the supersaturation is reached. The typical height of this supersaturation region shown in Fig. 5, a few $\mathrm{mm}$ at most, is not accessible to measurements currently carried out at Dome C. Consequently, to investigate the possibility of sublimation crystals' formation, we use the criteria 
a

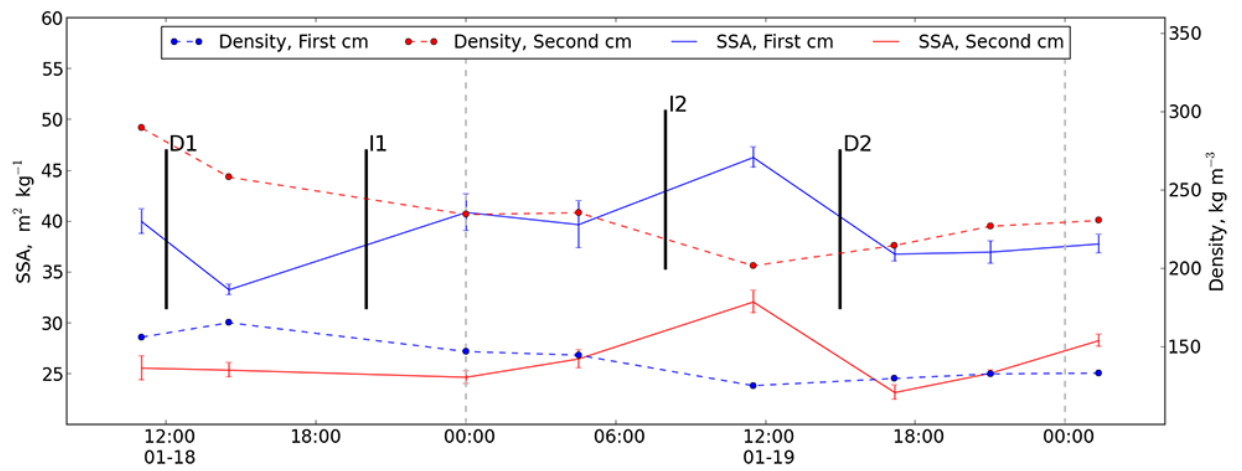

b

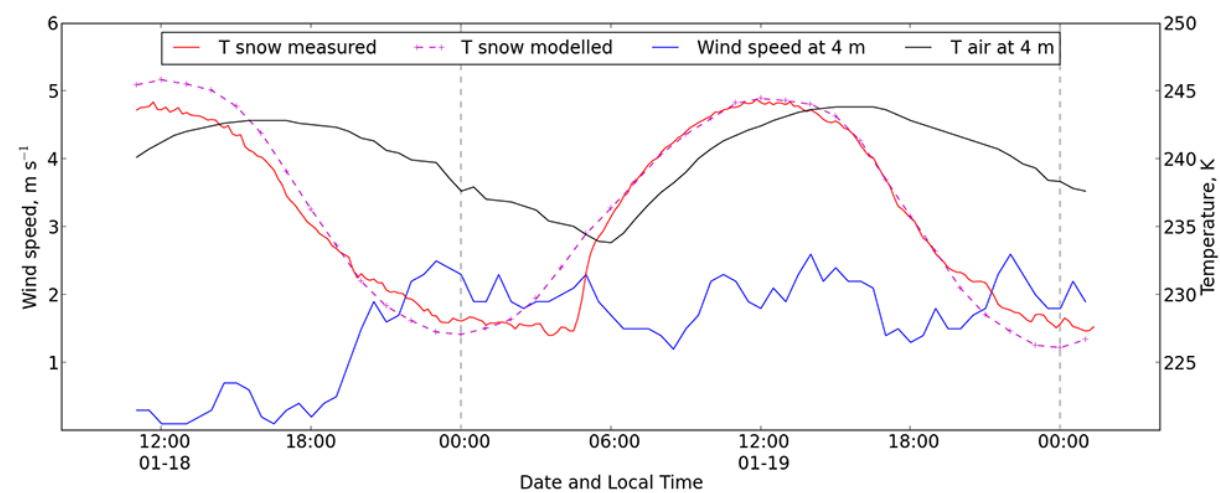

Figure 2. Time series of physical variables on 18 and 19 January 2009. Time is local time, GMT+08:00. (a) Snow SSA and density values. (b) Meteorological variables and simulated temperature with Crocus. Date is indicated in the lowest part of the $x$ axis and local time just above.

Table 2. Possible regimes for water vapor exchange as a function of environmental conditions for an unsaturated atmosphere. This table is adapted from the Table 1 of Style and Worster (2009).

\begin{tabular}{llll}
\hline Regime & Temperature conditions & Surface characteristics & Environmental conditions \\
\hline III & Air warmer than surface & Condensation supersaturated & $T_{\infty}>T_{i}$ and $\pi>(1+m \mu) e^{-m \mu}$ \\
IV & Air warmer than surface & Condensation unsaturated & $T_{\infty}>T_{i}$ and $\pi<(1+m \mu) e^{-m \mu}$ and $\pi>e^{-m \mu}$ \\
V & Surface warmer than air & Sublimation unsaturated & $T_{\infty}<T_{i}$ and $\pi<e^{-m \mu}$ or $T_{\infty}>T_{i}$ and $\pi<(1+m \mu) e^{-m \mu}$ \\
VI & Surface warmer than air & Sublimation supersaturated & $T_{\infty}<T_{i}$ and $\pi>(1+m \mu) e^{-m \mu}$ \\
\hline
\end{tabular}

of Style and Worster (2009) and compare the saturation ratio of the far field, taken in our study as the $4 \mathrm{~m}$ measurements, and the snow surface temperature simulated by Crocus.

Figure 6 depicts the saturation ratio $\left(\pi=p_{\infty} / p_{\text {sat }}\left(T_{\infty}\right)\right)$ versus $(1+m \mu) e^{-m \mu}$. The blue dots corresponds to the different times of the day for 17 January 2009, the red dots the same for 18 January and the green diamonds for 19 January. The black solid line is the $y=x$ line which separates regimes V (shaded area) and VI (white area). Dots are only plotted if the surface is warmer than the air, which only occurs during daytime. Regime VI (Table 2) is characterized by unsaturated far field and surface temperature higher than far field temperature. This corresponds to the regime required for the formation of sublimation crystals (Style and Worster, 2009).

Figure 6 shows that regime VI occurs on the morning (8:00 to $12: 00)$ of 18 January, when the air humidity is maximal and the snow is warmest. Our simulations therefore predict that sublimation crystals can indeed form, but only on the morning of 18 January, while we observed their formation also on 17 and 19 January. We explain this discrepancy as follows. Conditions for which sublimation crystals can form are very sensitive to the values of the temperature difference between the snow and the air and to the air relative humidity. In their work, Style and Worster (2009) investigated the possibility of frost flowers formation over ice. In this study, we observed the formation of sublimation crystals over snow, which is a porous material while ice is not. Consequently in our case, the water vapor can originate from below the snow surface. As seen in Figs. 3 and 5, during the day, the warmest point of the snowpack is located around $1 \mathrm{~cm}$ below the surface. This warm point facilitates the release of water vapor 

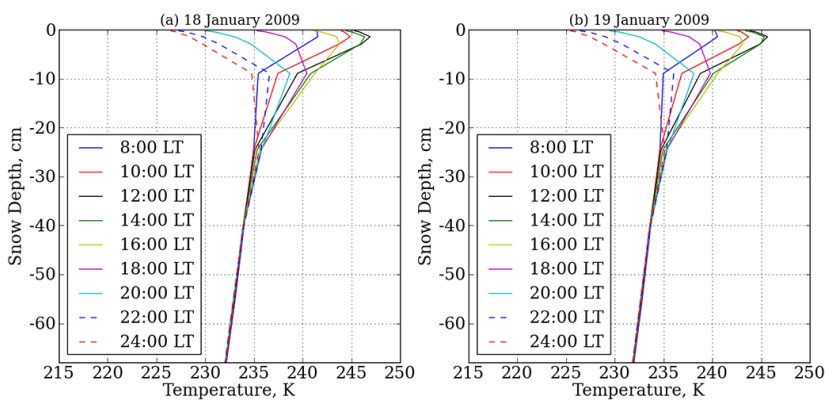

Figure 3. Simulated vertical temperature profiles for the upper layer of the snowpack on 18 June 2009 (left panel) and on 19 June 2009 (right panel) for several local times $(\mathrm{LT}=\mathrm{GMT}+8)$.

through ice sublimation and the formation of a supersaturation region just above the surface.

It may then be argued that not only snow surface temperature but also the temperature of the warmest point of the uppermost snowpack needs to be considered when assessing the conditions favorable for the formation of sublimation crystals. Style and Worster (2009) did not need to consider this because the ice surface they modeled is not porous and the water vapor source is indeed the ice-air interface. The temperatures of the snow surface and of the warmest point below the surface are determined, among other factors, by the thermal conductivity of snow. In our modeling study, the thermal conductivity was computed as a function of density following Yen's parameterization (1981). Although the parameterization has proven to be adequate for numerous snowpack conditions, density is not a perfect predictor of snow thermal conductivity, and snow mechanical properties also come into play, with harder snows being more conductive for a given density (Domine et al., 2011a). Here the surface snow at Dome C was very soft, likely implying a lower thermal conductivity than predicted by Yen (1981). This would generate a higher temperature below the snowpack surface. These considerations would imply that regime VI is found more often than predicted in Fig. 6 and would further increase the possibility of formation of sublimation crystals.

To illustrate these considerations, new simulations were thus run starting on 13 January with modified densities, using $100 \mathrm{~kg} \mathrm{~m}^{-3}$ for the first centimeter and $200 \mathrm{~kg} \mathrm{~m}^{-3}$ for the second centimeter which are lower than base run densities and lead to a lowered thermal conductivity. The Style and Worster regimes conditions were met for the different hours of the day are depicted in Fig. 7. These calculations were done in two ways. First, as previously done, the snow temperature used was the surface snow temperature (purple diamonds). Second, the snow temperature used was that $1 \mathrm{~cm}$ below the surface (snow warmest point in light blue circles).

Figure 7 shows that condensation happens each night in all the cases (regime IV), confirming that surface hoar crystals do form. Regime VI (formation of sublimation crystals) also

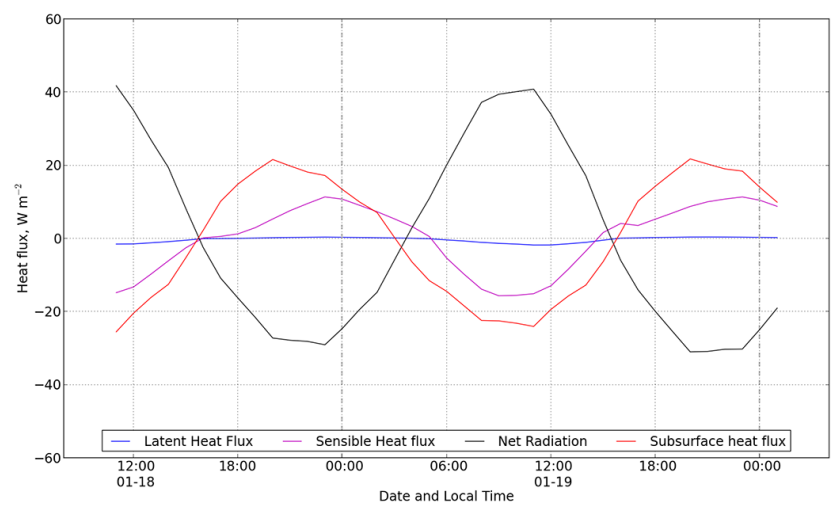

Figure 4. Simulated energy fluxes at the air-snow interface. Positive atmospheric latent heat implies snow sublimation; positive sensible heat leads to transfer of energy from the snow to the atmosphere. Positive net radiation would be leading to heating of the snow surface. Positive subsurface heat flux means a transfer of energy from the snow towards the atmosphere. Date is indicated in the lowest part of the $x$ axis and local time just above.

happens each day around noon when considering that the vapor exchanges are initiated at the warmest point of the snowpack and using a modified density lower than the field value. While using field measured density (red triangle), regime VI still occurs on 17 and 18 January.

In summary, besides the commonly described formation of surface hoar crystals, our analysis predicts that sublimation crystals form every day of our study period, if the formalism of Style and Worster (2009) is adapted to the conditions applicable to a porous snow surface. Formation can take place under clear sky and low wind because it allows a maximum cooling at the snow surface and heating below that surface so that a high temperature gradient exists and generates vapor water fluxes. The growth rate of sublimation crystals has been shown to be sensitive to the snow density which impacts the thermal profile of the upper snow layers and therefore water vapor fluxes.

These processes result in daily changes in snow physical properties so that daily variations of snow albedo are expected. These will be explored in the next section, together with their possible impact on the surface mass balance.

\section{Discussion}

Using the snow layers physical variables SSA, density and thickness, we can calculate the albedo of the snowpack if we assume a plane-parallel geometry. The snow stratigraphy used for the calculations are the SSA and density of the top $2 \mathrm{~cm}$ shown in Fig. 2a. Below, the mean properties of the Dome C snowpack are used, as detailed in Gallet et al. (2011). Briefly, a $3 \mathrm{~cm}$-thick layer of SSA $=30.9 \mathrm{~m}^{2} \mathrm{~kg}^{-1}$ and density $=317 \mathrm{~kg} \mathrm{~m}^{-3}$, and a $195 \mathrm{~cm}$-thick layer of $\mathrm{SSA}=17.3 \mathrm{~m}^{2} \mathrm{~kg}^{-1}$ and density $=351 \mathrm{~kg} \mathrm{~m}^{-3}$ were added 


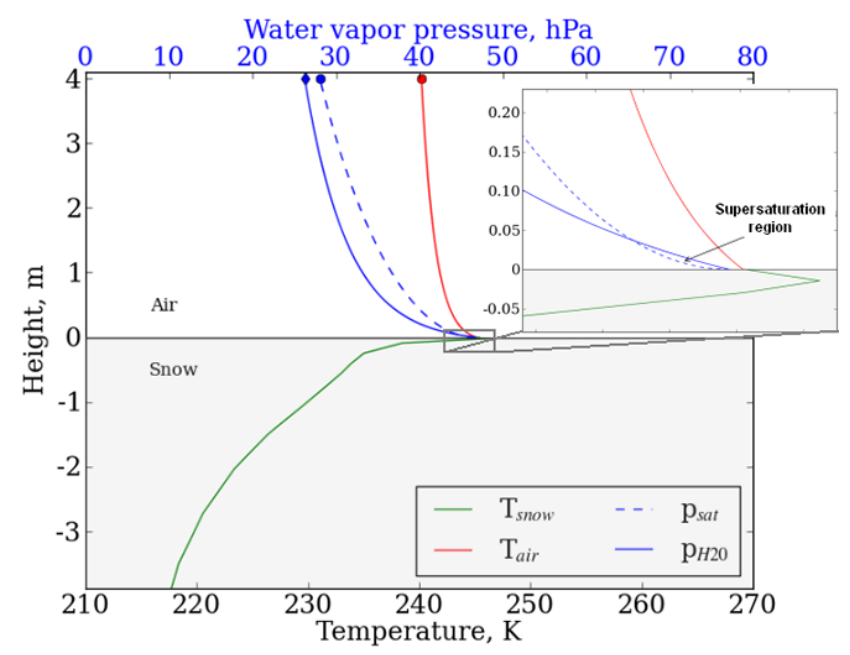

Figure 5. Schematic diagram of temperature and water vapor pressure for the air-snow system. The figure is adapted from Fig. 2 of Style and Worster (2009). The snow temperature is simulated by Crocus on 18 January at 11:00 LT. The blue and red dots and the blue diamond are calculated from $4 \mathrm{~m}$ measurements. The $T$, water vapor pressure and saturation pressure profiles between the snow surface and $4 \mathrm{~m}$ height are drawn from Fig. 2 of Style and Worster (2009).

to calculate the albedo of an optically semi-infinite medium. The DIScrete ORdinate radiative Transfer model (DISORT, Stamnes et al, 1988) wich computes plane parallel radiative transfer equations was used to calculate the spectral albedo of the snowpack. The SBDART (Santa Barbara DISORT Atmospheric Radiative Transfer) model (Ricchiazzi et al., 1998) was used to determine the downward spectral irradiance at the surface. Using both models outputs, we calculated the broadband albedo of the snowpack for clear conditions. Results are presented in Fig. 8. Calculations were done under two sets of conditions in order to quantify the effect of the snow physical properties. For the black curve, the solar zenith angle (SZA) is set constant to $70^{\circ}$. For the red curve, the SZA is the real value at measurement time. The red curve shows that the highest values are calculated at midnight when the SZA is highest so that photons can be backscattered more easily (Warren, 1982).

The maximum broadband albedo variation calculated is 0.062 between $14: 30$ and midnight on 18 January. The SZA contributes $89 \%$ to this while changes in snow physical properties contribute the remaining $11 \%$ and are responsible for a variation of 0.007 in albedo. This is not negligible as it leads to an instantaneous local forcing of $6 \mathrm{~W} \mathrm{~m}^{-2}$ at 14:30. Between 14:30, 18 January and noon 19 January, the SSA increase due to the growth of sublimation crystals leads to an albedo increase of 0.012 and to a forcing of $10 \mathrm{~W} \mathrm{~m}^{-2}$ (black curve of Fig. 8). Using Crocus, we calculate that increasing the albedo by 0.012 over $24 \mathrm{~h}$ on 19 January leads to a maximum surface temperature drop of $0.45 \mathrm{~K}$ and an av-

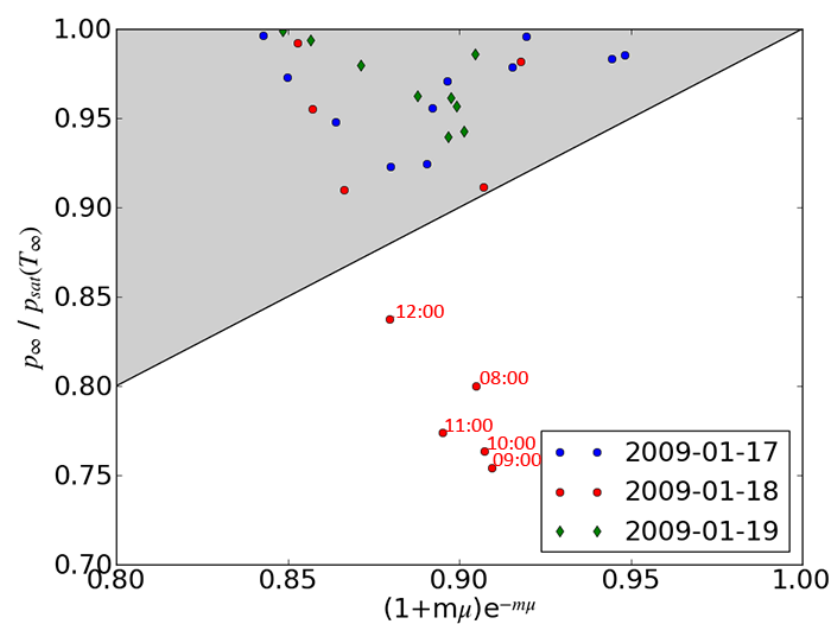

Figure 6. Atmosphere saturation ratio as a function of $(1+m \mu) e^{-m \mu}$. The different markers correspond to the three days of the measurements period. Dots are only indicated if the surface is warmer than the far field. The white area corresponds to regime VI (Table 1) and the greyed area to regime V. Time given is local time.

erage drop over the day of $0.33 \mathrm{~K}$. However, a drop in the SSA does not necessarily translate into a drop in albedo, as the increasing solar zenith angle has a prevailing effect over the decreasing SSA (red curve of Fig. 8). This result is similar to that predicted by (Picard et al., 2012) on the effect of increased precipitation on the surface temperature of the Antarctic plateau, confirming that snow SSA is a critical factor in the energy budget of Antarctica.

Note that this calculation does not take into account the albedo change due to changes in surface roughness (Hudson and Warren, 2007). As seen in Fig. 1, crystal formation induces a change of surface roughness. The structures are very small, a few $\mathrm{mm}$, and the effect of such small structures on albedo have never been quantified, even though it might reach a few percent (Warren et al., 1998). This should be also quantified in future work.

Our observations show significant exchanges of water vapor between the snow and the atmosphere. We have demonstrated that some of the crystals formed were sublimation crystals, while others were surface hoar crystals, showing that water vapor fluxes were important and in both directions, affecting the surface mass balance in a complex manner. Figure 4 shows that sublimation predominates over condensation, so that it may be deduced that water vapor exchanges lead to an overall mass loss. However, uncertainties in the calculations do not allow such a clear-cut conclusion. Indeed, this result is based on simulations by Crocus, which does not treat the formation of sublimation crystals and the resulting modifications in snow SSA and roughness. Therefore we cannot, at this stage, quantify with great accuracy the surface energy and mass budgets under the clear sky and low wind conditions of this study. Future work will be devoted 


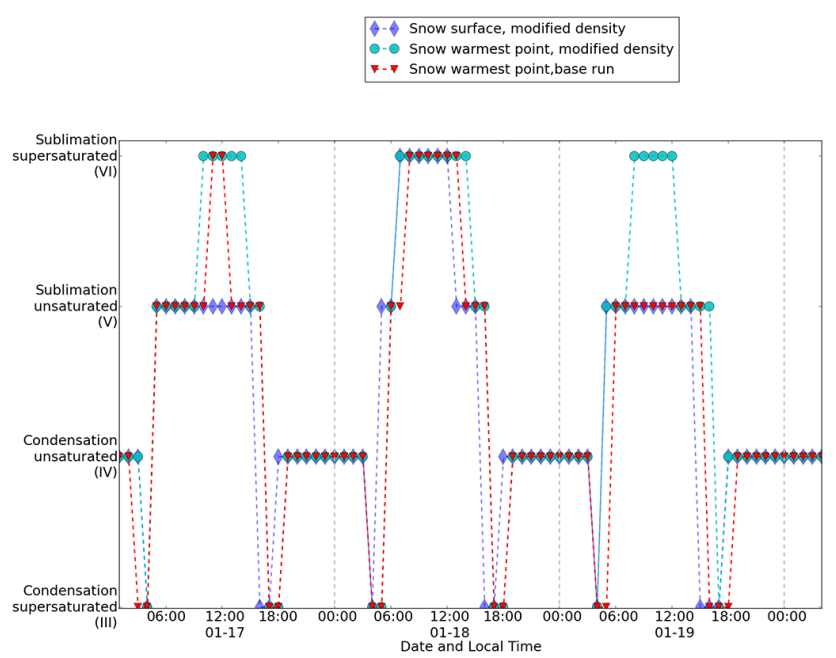

Figure 7. Determinations of the regimes of Style and Worster (2009) with modified density values and taking the snow temperature $1 \mathrm{~cm}$ below the surface. The purple diamonds correspond to a simulation with modified density and where the snow temperature is taken as the surface temperature. The light blue circles are also for modified density but the snow temperature is taken $1 \mathrm{~cm}$ below the surface. The red triangles are the results of simulations with measured density and snow temperature from $1 \mathrm{~cm}$ below the surface. Date is indicated in the lowest part of the $x$ axis and local time just above.

to this task and in particular to measure the albedo and mass balance of the snow. For an accurate mass balance, the density of snow layers can be measured, but investigating the top $2 \mathrm{~cm}$ is likely not sufficient, as deeper layers may also contribute to sublimating fluxes.

Quantifying the fractions of depth hoar and sublimation crystals that formed would help to constrain the surface mass balance. Doing this from crystal shape observations appears very difficult because it is not clear that both formation processes always lead to different shapes. At Alert, in the Canadian High Arctic, (Cabanes et al., 2002) observed featherlike crystals that were positively identified as surface hoar using a teflon tarp that blocked possible vapor fluxes from the snowpack to the atmosphere. These surface hoar crystals had many similarities with the crystals of Fig. 1. Sublimation crystals are therefore difficult to differentiate from surface hoar, and indeed (Gow, 1965) seems to have confused some sublimation crystals with surface hoar (which he calls hoar frost). Likewise, it would be interesting to relate SSA variations of Fig. 2 to the growth or disappearance of crystals but more detailed observations would be required to avoid misleading interpretations. For example, an SSA increase could be due to the formation of new crystals but also to the sublimation of existing ones, which would reduce their size and therefore increase their SSA. Observations of snow physical properties at a very high time resolution, ideally coupled with vapor flux measurements is required to understand the micro-

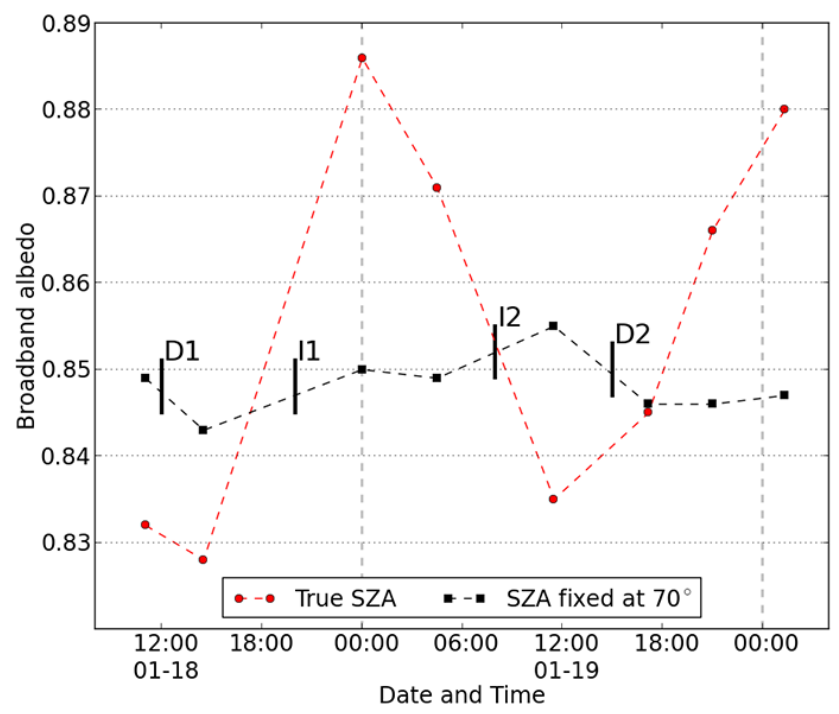

Figure 8. Broadband albedo, 18-19 January 2009 for local time $(\mathrm{GMT}+8: 00)$. Calculations were done using DISORT with two scenarios: SSA variations are always taken into account while the effect of the solar zenith angle (SZA) is either taken into account or not. Date is indicated in the lowest part of the $x$ axis and local time just above.

physical changes and their impact on macroscopic properties such as SSA.

An alternative method to quantify the relative contribution of sublimation and surface hoar crystals to the observed clusters may come from isotopic studies. Since surface hoar crystals form from atmospheric water vapor while sublimation crystals come from snow water vapor, the isotopic signature may be different (Neumann et al., 2008; Steen-Larsen et al., 2014), and this might be usable to quantify water vapor exchanges and therefore improve our understanding of the processes involved in the mass balance of the East Antarctic Ice Sheet.

\section{Conclusions}

This study, performed under conditions of clear sky and low wind frequently encountered in summer on the Antarctic plateau, highlights the highly dynamic character of the snow surface of the Antarctic plateau under these conditions. We conclude that water vapor exchanges between the snow surface and the atmosphere take place in both directions. At night, downward water vapor fluxes lead to the formation of surface hoar crystals while in the daytime, upward fluxes lead to the growth of sublimation crystals.

This dynamic interface has many important consequences for the mass and energy budgets of the Antarctic plateau. The growth of depth hoar and sublimation crystals dramatically changes the snow structure, SSA, and density, as well as surface roughness, leading to significant changes in albedo and 
therefore surface temperature. We have calculated that the albedo change due to modifications in snow physical properties was up to 0.012 , which represents a local forcing at noon of $-10 \mathrm{~W} \mathrm{~m}^{-2}$ at the snow surface.

Acknowledgements. This work was funded by the French Polar Institute (IPEV) under grant Nite DC, no. 1011. We thank G. Picard for discussions on energy and mass exchanges at the surface. We are grateful to L. Arnaud for providing us with the snow surface temperature data and the BSRN network for the radiation data. We thank all the technical staff of the Dome Concordia station for their help during the campaign. C. Genthon kindly provided data at $4 \mathrm{~m}$ from the tower. JCG was also supported through the project "Long range transport of Black Carbon and its effect on snow albedo in North East China and in the Arctic" funded by the Norwegian Research council (Norklima program, project 193717) and "Satellite Remote Sensing of Atmosphere-Surface Systems and Ground Truth Measurements" funded by the Norwegian Research Council (Norklima program, project 209681/E10).

Edited by: M. Schneebeli

\section{References}

Aoki, T., Fukabori, M., Hachikubo, A., Tachibana, Y., and Nishio, F.: Effects of snow physical parameters on spectral albedo and bidirectional reflectance of snow surface, J. Geophys. Res.Atmos., 105, 10219-10236, 2000.

Bintanja, R. and Vandenbroeke, M. R.: The surface-energy balance of antarctic snow and blue ice, J. Appl. Meteorol., 34, 902-926, doi:10.1175/1520-0450(1995)034<0902:tseboa>2.0.co;2, 1995.

Brun, E., Six, D., Picard, G., Vionnet, V., Arnaud, L., Bazile, E., Boone, A., Bouchard, A., Genthon, C., Guidard, V., Le Moigne, P., Rabier, F., and Seity, Y.: Snow/atmosphere coupled simulation at Dome C, Antarctica, J. Glaciol., 57, 721-736, 2011.

Brun, E., Vionnet, V., Boone, A., Decharme, B., Peings, Y., Valette, R., Karbou, F., and Morin, S.: Simulation of northern Eurasian local snow depth, mass and density using a detailed snowpack model and meteorological reanalysis, J. Hydrometeorol., 14, 203-214, doi:10.1175/jhm-d-12-012.1, 2013.

Cabanes, A., Legagneux, L., and Domine, F.: Evolution of the specific surface area and of crystal morphology of Arctic fresh snow during the ALERT 2000 campaign, Atmos. Environ., 36, 27672777, 2002.

Champollion, N., Picard, G., Arnaud, L., Lefebvre, E., and Fily, M.: Hoar crystal development and disappearance at Dome C, Antarctica: observation by near-infrared photography and passive microwave satellite, The Cryosphere, 7, 1247-1262, doi:10.5194/tc-7-1247-2013, 2013.

Colbeck, S. C.: An overview of seasonal snow metamorphism, Rev. Geophys., 20, 45-61, 1982.

Colbeck, S. C.: Snow-crystal growth with varying surface temperatures and radiation penetration, J. Glaciol., 35, 23-29, 1989.

Conger, S. M. and McClung, D. M.: Comparison of density cutters for snow profile observations, J. Glaciol., 55, 163-169, 2009.
Dee, D. P., Uppala, S. M., Simmons, A. J., Berrisford, P., Poli, P., Kobayashi, S., Andrae, U., Balmaseda, M. A., Balsamo, G., Bauer, P., Bechtold, P., Beljaars, A. C. M., van de Berg, L., Bidlot, J., Bormann, N., Delsol, C., Dragani, R., Fuentes, M., Geer, A. J., Haimberger, L., Healy, S. B., Hersbach, H., Holm, E. V., Isaksen, L., Kallberg, P., Kohler, M., Matricardi, M., McNally, A. P., Monge-Sanz, B. M., Morcrette, J. J., Park, B. K., Peubey, C., de Rosnay, P., Tavolato, C., Thepaut, J. N., and Vitart, F.: The ERA-Interim reanalysis: configuration and performance of the data assimilation system, Q. J. Roy. Meteorol. Soc., 137, 553597, doi:10.1002/qj.828, 2011.

Domine, F., Taillandier, A. S., Simpson, W. R., and Severin, K.: Specific surface area, density and microstructure of frost flowers, Geophys. Res. Lett., 32, L13502, 10.1029/2005g1023245, 2005.

Domine, F., Taillandier, A. S., and Simpson, W. R.: A parameterization of the specific surface area of seasonal snow for field use and for models of snowpack evolution, J. Geophys. Res.-Earth Surface, 112, F02031, doi:10.1029/2006jf000512, 2007.

Domine, F., Bock, J., Morin, S., and Giraud, G.: Linking the effective thermal conductivity of snow to its shear strength and its density, J. Geophys. Res., 116, F04027, doi:10.1029/2011JF002000, 2011a.

Domine, F., Gallet, J. C., Barret, M., Houdier, S., Voisin, D., Douglas, T., Blum, J. D., Beine, H., and Anastasio, C.: The specific surface area and chemical composition of diamond dust near Barrow, Alaska, J. Geophys. Res., 116, D00R06, doi:10.1029/2011JD016162, 2011b.

Fierz, C., Armstrong, R. L., Durand, Y., Etchevers, P., Greene, E., McClung, D. M., Nishimura, K., Satyawali, P. K., and Sokratov, S. A.: The International classification for seasonal snow on the ground UNESCO-IHP, ParisIACS Contribution No 1, 80, 2009.

Flanner, M. G. and Zender, C. S.: Linking snowpack microphysics and albedo evolution, J. Geophys. Res.-Atmos., 111, D12208, doi:10.1029/2005jd006834, 2006.

Fréville, H., Brun, E., Picard, G., Tatarinova, N., Arnaud, L., Lanconelli, C., Reijmer, C., and van den Broeke, M.: Using MODIS land surface temperatures and the Crocus snow model to understand the warm bias of ERA-Interim reanalyses at the surface in Antarctica, The Cryosphere Discuss., 8, 55-84, doi:10.5194/tcd8-55-2014, 2014.

Gallet, J.-C., Domine, F., Zender, C. S., and Picard, G.: Measurement of the specific surface area of snow using infrared reflectance in an integrating sphere at 1310 and $1550 \mathrm{~nm}$, The Cryosphere, 3, 167-182, doi:10.5194/tc-3-167-2009, 2009.

Gallet, J.-C., Domine, F., Arnaud, L., Picard, G., and Savarino, J.: Vertical profile of the specific surface area and density of the snow at Dome C and on a transect to Dumont D'Urville, Antarctica - albedo calculations and comparison to remote sensing products, The Cryosphere, 5, 631-649, doi:10.5194/tc-5-6312011, 2011.

Genthon, C., Town, M. S., Six, D., Favier, V., Argentini, S., and Pellegrini, A.: Meteorological atmospheric boundary layer measurements and ECMWF analyses during summer at Dome C, Antarctica, J. Geophys. Res.-Atmos., 115, D05104, doi:10.1029/2009jd012741, 2010.

Gow, A. J.: On the accumulation and seasonal stratification of snow at the South Pole, J. Glaciol., 5, 467-477, 1965. 
Grenfell, T. C. and Warren, S. G.: Representation of a nonspherical ice particle by a collection of independent spheres for scattering and absorption of radiation, J. Geophys. Res.-Atmos., 104, 31697-31709, 1999.

Hudson, S. R. and Warren, S. G.: An explanation for the effect of clouds over snow on the top-of-atmosphere bidirectional reflectance, J. Geophys. Res., 112, D19202, doi:10.1029/2007jd008541, 2007.

Legagneux, L., Cabanes, A., and Domine, F.: Measurement of the specific surface area of 176 snow samples using methane adsorption at $77 \mathrm{~K}$, J. Geophys. Res.-Atmos., 107, 4335, 10.1029/2001jd001016, 2002.

Libbrecht, K. G.: The physics of snow crystals, Rep. Prog. Phys., 68, 855-895, doi:10.1088/0034-4885/68/4/r03, 2005.

McGuffie, K. and Henderson-Sellers, A.: The diurnal hysteresis of snow albedo, J. Glaciol., 31, 188-189, 1985.

Minkoff, I. and Lux, B.: Instability criteria for growth of a hopper crystal related to spiral eutectic morphology, J. Crystal Growth, 22, 163-165, doi:10.1016/0022-0248(74)90134-1, 1974.

Mullins, W. W. and Sekerka, R. F.: Morphological stability of a prticle growing by diffusion or heat flow, J. Appl. Phys., 34, 323 329, doi:10.1063/1.1702607, 1963.

Neumann, T. A., Albert, M. R., Lomonaco, R., Engel, C., Courville, Z., and Perron, F.: Experimental determination of snow sublimation rate and stable-isotopic exchange, Ann. Glaciol., 49, 1-6, 2008.

Orheim, O.: Surface snow metamorphosis on the Antarctic plateau, in: Norsk Polarinstitutt Arbok 1966, Norsk Polarinstitutt, Oslo, 84-91, 1968.

Perovich, D. K. and Richter-Menge, J. A.: Surface characteristics of lead ice, J. Geophys. Res., 99, 16341-16350, 1994.

Picard, G., Domine, F., Krinner, G., Arnaud, L., and Lefebvre, E.: Inhibition of the positive snow-albedo feedback by precipitation in interior Antarctica, Nat. Clim. Change, 2, 795-798, doi:10.1038/nclimate1590, 2012.

Pirazzini, R.: Surface albedo measurements over Antarctic sites in summer, J. Geophys. Res.-Atmos., 109, D20118, doi:10.1029/2004jd004617, 2004.

Ricchiazzi, P., Yang, S. R., Gautier, C., and Sowle, D.: SBDART: A research and teaching software tool for plane-parallell radiative transfer in the Earth's atmosphere, B. Am. Meteorol. Soc., 79, 2101-2114, 1998.

Robinson, D. A., Dewey, K. F., and Heim, R. R.: Global snow cover monitoring - an update, B. Am. Meteorol. Soc., 74, 1689-1696, 1993.

Stamnes, K., Tsay, S. C., Wiscombe, W., and Jayaweera, K.: Numerically stable algorithm for discrete-ordinate-method radiative-transfer in multiple-scattering and emitting layered media, Appl. Opt., 27, 2502-2509, 1988.
Steen-Larsen, H. C., Masson-Delmotte, V., Hirabayashi, M., Winkler, R., Satow, K., Prié, F., Bayou, N., Brun, E., Cuffey, K. M., Dahl-Jensen, D., Dumont, M., Guillevic, M., Kipfstuhl, S., Landais, A., Popp, T., Risi, C., Steffen, K., Stenni, B., and Sveinbjörnsdottír, A. E.: What controls the isotopic composition of Greenland surface snow?, Clim. Past, 10, 377-392, doi:10.5194/cp-10-377-2014, 2014.

Style, R. W. and Worster, M. G.: Frost flower formation on sea ice and lake ice, Geophys. Res. Lett., 36, L11501, doi:10.1029/2009g1037304, 2009.

Taillandier, A. S., Domine, F., Simpson, W. R., Sturm, M., and Douglas, T. A.: Rate of decrease of the specific surface area of dry snow: Isothermal and temperature gradient conditions, J. Geophys. Res.-Earth Surface, 112, F03003, doi:10.1029/2006jf000514, 2007.

Van As, D., Van Den Broeke, M., and De Wal, R.: Daily cycle of the surface layer and energy balance on the high Antarctic Plateau, Antarct. Sci., 17, 121-133, doi:10.1017/s095410200500252x, 2005.

Van den Broeke, M., Reijmer, C., Van As, D., and Boot, W.: Daily cycle of the surface energy balance in Antarctica and the influence of clouds, Int. J. Climatol., 26, 1587-1605, doi:10.1002/joc.1323, 2006.

Vionnet, V., Brun, E., Morin, S., Boone, A., Faroux, S., Le Moigne, P., Martin, E., and Willemet, J. M.: The detailed snowpack scheme Crocus and its implementation in SURFEX v7.2, Geosci Model Dev., 5, 773-791, doi:10.5194/gmd-5-773-2012, 2012.

Warren, S. G.: Optical-properties of snow, Rev. Geophys., 20, 6789, 1982.

Warren, S. G. and Clarke, A. D.: Soot in the atmosphere and snow surface of Antarctica, J. Geophys. Res., 95, 1811-1816, 1990.

Warren, S. G., Brandt, R. E., and Hinton, P. O.: Effect of surface roughness on bidirectional reflectance of Antarctic snow, J. Geophys. Res.-Planets, 103, 25789-25807, 1998.

Weller, G.: The heat and mass balance of snow dunes on the central Antarctic plateau, J. Glaciol., 8, 277-284, 1969.

Yen, Y.-C.: Review of thermal properties of snow, ice, and sea ice, United States Army Corps of Engineers, Hanover, N.H., USACRREL Report 81-10, 1-27, 1981.

Zhou, X. B., Li, S. S., and Stamnes, K.: Effects of vertical inhomogeneity on snow spectral albedo and its implication for optical remote sensing of snow, J. Geophys. Res., 108, D4738, doi:10.1029/2003jd003859, 2003. 